\title{
The Accelerated Window Work Method Using Vertical Formwork for Tall Residential Building Construction
}

\author{
Taehoon Kim ${ }^{1}$, Hyunsu Lim ${ }^{2, *}$, Chang-Won Kim ${ }^{2}$, Dongmin Lee ${ }^{1}$, Hunhee Cho ${ }^{1}$ \\ and Kyung-In Kang ${ }^{1}$ \\ 1 School of Civil, Environmental and Architectural Engineering, Korea University, Anam-Dong, Seongbuk-Gu, \\ Seoul 02841, Korea; kimth0930@hanmail.net (T.K.); ldm1230@korea.ac.kr (D.L.); hhcho@korea.ac.kr (H.C.); \\ kikang@korea.ac.kr (K.-I.K.) \\ 2 BK21 Innovative Leaders for Creating Future Value in Civil Engineering, Korea University, Anam-Dong, \\ Seongbuk-Gu, Seoul 02841, Korea; wraith304@korea.ac.kr \\ * Correspondence: iroze00@korea.ac.kr; Tel.: +82-2-921-5920
}

Received: 29 January 2018; Accepted: 7 February 2018; Published: 9 February 2018

\begin{abstract}
In tall residential building construction, there is a process gap between the window work and the structural work. This process gap extends the total period of the project and increases its cost. In addition, as this process gap increases external exposure to noise and dust, it negatively affects the environment of a site and often causes civil complaints. This paper introduces a new window work process called the accelerated window work (AWW) method, which minimizes the process gap and can reduce construction cost and duration and the number of civil complaints. We provide technical details and management elements of the AWW method with a case study that demonstrates the reductions in construction costs and duration compared with the conventional method. This work contributes to the body of knowledge in window work in tall buildings by introducing and validating a new window work method and process. The proposed method will be useful for practitioners who are under short-term constraints.
\end{abstract}

Keywords: accelerated window work method; vertical formwork; tall residential building construction; window work

\section{Introduction}

In tall residential building construction, there is a process gap between the window work and the structural work [1,2]. For tall building structural work, large formwork with several working platforms is generally installed outside the building [3]. These platforms limit the operation height of the construction hoists that lift window components. In addition, because a residential building has many walls and small windows compared with office buildings, there is a relatively large difference in productivity between the structural work and window work, which increases the process gap between these types of work. Because of these spatial constraints and productivity differences, window construction begins after several floors of structural work.

This process gap extends the duration of the project and increases the cost of the entire construction [4]. As the window work is on the critical path of the process, the entire duration of construction is delayed if window work is delayed. In addition, because the construction section between the structural work and the window work is open externally, safety facilities such as safety rails and nets must be installed in this section. These additional safety facilities increase material and labor costs by repetitive installation during the construction. A larger gap between the two processes increases the effect on the duration and cost of construction. In addition, this process gap negatively 
affects the environment of a site and often causes civil complaints because it increases external exposure to noise and dust. In particular, dust caused by construction-related activities is a major source of particulate matter (PM) in the urban atmosphere [5], which has been associated with higher rates of morbidity and mortality in urban areas [6,7].

To solve this problem, various attempts have been made to reduce this process gap $[2,8]$. One method is to raise the maximum floor of hoist operation by modifying the platform of the vertical formwork above where the hoist is installed. With this method, window construction can start one or two floors earlier. Another method is to reduce the unit of construction for window work. This method can reduce the gap from the structural work by performing window installation more frequently. However, these methods cannot fundamentally eliminate the gaps.

Previous studies on window works have focused on preventing delays to the period of window work by management methods, or increasing efficiency by automated construction [9-13]. However, these studies have not solved the process gaps. Kang et al. [14] proposed the concept of using an auto climbing system independently to perform external insulation and finishing work. However, this method was costly because of the additional system, which must operate five or more floors below the formwork floor. Lim et al. [15] proposed a window proximity-tracking method to reduce the process gap. However, they proposed only the concept and did not perform economic analysis based on an actual application in a construction site.

This study introduces the accelerated window work (AWW) method using vertical forms for tall residential building construction, which can reduce the vertical constraint between structural work and window work. We describe the advantages of the AWW method compared with conventional construction methods in terms of the construction period and the costs through a case study of a tall residential building. The proposed method will help construction managers to ensure cost-effective alternatives in tall building constructions with limited duration.

\section{The Conventional Window Work Method for Tall Residential Building Construction}

Figure 1 shows the conventional process of window work and structural work in tall residential building construction.

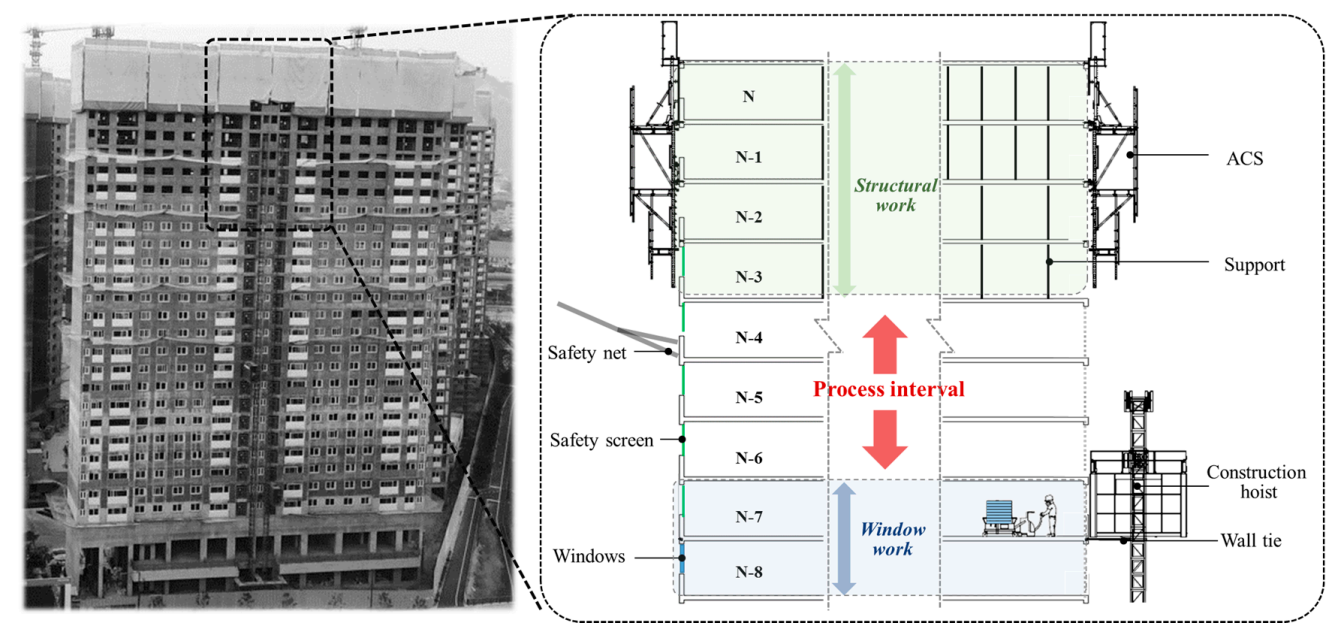

Figure 1. Schematic diagram of conventional processes for the structural work and window work.

From the $\mathrm{N}$-th floor, which is the structural work floor, to the ( $\mathrm{N}-2)$-th floor, curing is performed, and supports are dismantled on the (N - 3)-th floor. The automatic climbing system (ACS) is installed from the $\mathrm{N}$-th floor to the $(\mathrm{N}-2)$-th floor. From the $(\mathrm{N}-4)$-th to the $(\mathrm{N}-6)$-th floor, where windows cannot be lifted into place and installed, temporary safety facilities, such as safety nets and guardrails, are installed to prevent accidents involving falling workers and dropping objects, while dust filter nets 
or similar resources are installed to prevent air pollution around the site via dust scattering. Windows can be lifted and installed on the ( $\mathrm{N}-7)$-th floor.

The window work in tall residential building constructions is generally performed with an interval of five or more floors. Because the productivity of window work is higher than that of structural work, window work teams only work when there is a sufficient quantity of window work available.

After structural work on all floors is completed, the caulking work for external windows is performed outside by using a suspended working platform or gondola with a wire rope that is secured to the top of the building. This work method potentially involves falls by workers because of the unstable working environment.

As a result, the conventional window work method has a vertical constructability constraint of six or more floors between structural work and window work. This increases total construction duration because of the late start time of the window work and increases costs directly due to the safety facilities required as well as indirectly due to the extended construction period.

\section{The AWW Method Using a Vertical Formwork for Tall Residential Building Construction}

In the AWW method, window work is carried out on the lower work plates of the ACS while structural work is performed on the upper work plates, and window work is conducted in the same work cycle as structural work (Figure 2). This method removes the vertical constructability constraint between the two processes. It allows for an earlier start of finishing work and reduces the total period of construction by an amount equal to the decrease of the process gap between structure work and window work. In this method, an additional level of work plate is added to the ACS, and window work is performed on this level. As in the traditional method, the structural work is performed from the $\mathrm{N}$-th to the $(\mathrm{N}-2)$-th floor, and the support is dismantled on the $(\mathrm{N}-3)$-th floor. Windows are lifted to the (N - 2)-th floor by construction hoists to complete window work on the (N-2)-th and $(\mathrm{N}-3)$-th floors. To apply the AWW method, the following core technologies and management efforts are required: (1) a vertically extended ACS, (2) construction hoist operation, and (3) window work cycle management.

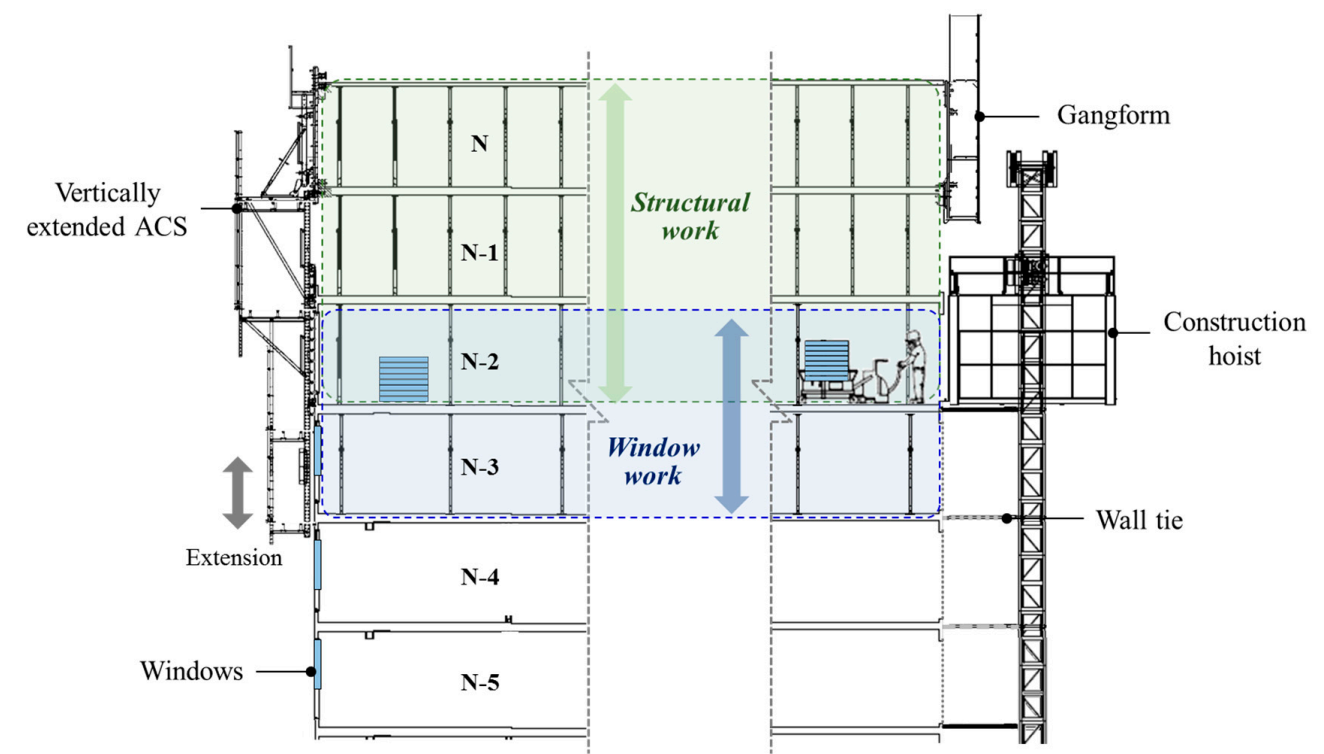

Figure 2. Schematic diagram of the AWW method.

\subsection{Vertically Extended ACS}

To perform window work in the ACS, the additional work plate should be installed on the bottom of the ACS, which requires some simple modifications. First, the vertically extended ACS requires structural strengthening because of the increase in self-weight and workloads. Second, the height of 
the work plate between the ( $\mathrm{N}-2)$-th and $(\mathrm{N}-3)$-th floors is adjusted to allow workers to perform window work outside. Finally, pollution prevention plates are installed on the work plate below the structure work floor, which prevents windows from being polluted by concrete paste from the upper floor.

\subsection{Construction Hoist Operation}

To lift window materials to the ( $\mathrm{N}-2)$-th floor, some of the construction hoists should be able to access this floor. Some modifications of the construction hoist operation method are required. First, the extension cycle of the hoistway is shortened. In the conventional method, the hoistway is extended at intervals of three floors considering the finishing work cycle. However, in the AWW method, the hoistway should be extended at intervals of one floor to lift windows to each floor. Second, a gangform that has no work plates should be installed above the construction hoist to avoid spatial interference with the construction hoist. The formwork system is lifted by a tower crane. This enables the construction hoist to access the ( $\mathrm{N}-2)$-th floor for window work.

\subsection{Window Work Cycle Management}

In the AWW method, the window work and the structural work are performed on the same ACS that climbs with the cycle of structural work, typically 4-7 days per floor. The window work on a floor should therefore be completed within the cycle of structural work. The window work crew would work with a lower work quantity but a shorter cycle. In the conventional method, a window work crew comes on site when windows are required for five or more floors; in the AWW method, they must install windows on one floor within the cycle of structural work. This requires some changes in window work cycle management.

First, it is important to ensure the minimum quantity of work for the window work crew. This can be achieved by appropriately zoning the workspace. Second, the construction manager should ensure an optimal stock of windows on each floor so as not to delay the window work. If they are not hoisted in advance and the window work is delayed, the structural work in the critical path would be delayed, which extends the total construction period.

As noted, the AWW method solves the vertical constructability constraint of the conventional method. In the AWW method, the window work is performed on the (N - 3)-th floor, while structural work proceeds on the N-th floor, which allows finishing work to start four or more floors earlier than the conventional method. Moreover, there are no openings that have the potential for fall accidents because the windows are installed in the ACS on every floor. A workspace enclosed by windows improves work safety and prevents noise and dust from being released outside. Furthermore, additional safety facilities and temporary facilities for openings are no longer required, thereby decreasing costs.

\section{Case Study}

\subsection{Case Description}

The AWW method was applied to two mixed-use residential buildings: a 36-story building (Building A) and a 33-story building (Building B) located in Gongneung-dong, Seoul, South Korea. The construction period was about three years and one month. Figure 3 shows the layout plan and cross-section of this project. Commercial facilities are located from the first floor to the third floor, and residential facilities from the fourth floor to the top floor. Fire escape floors are located on the 31st and 28th floors.

The ACS used for external wall formwork was installed on the outside of the buildings, and aluminum forms were used for the internal formwork. Plastic window frames were used, and there were 34 windows per floor for Building A, taking up an area of $110 \mathrm{~m}^{2}$. For lifting materials, one construction hoist in each building and one tower crane for the site were installed. 
In the scheduling management of this project, the start time of finishing work was a critical factor because the total construction period was short, and the focus was placed on finishing work because of the characteristics of tall residential buildings. In addition, the start of structural work was delayed by about a month compared with the planned schedule. For this reason, the construction managers decided to apply the AWW method from the time the ACS was installed.

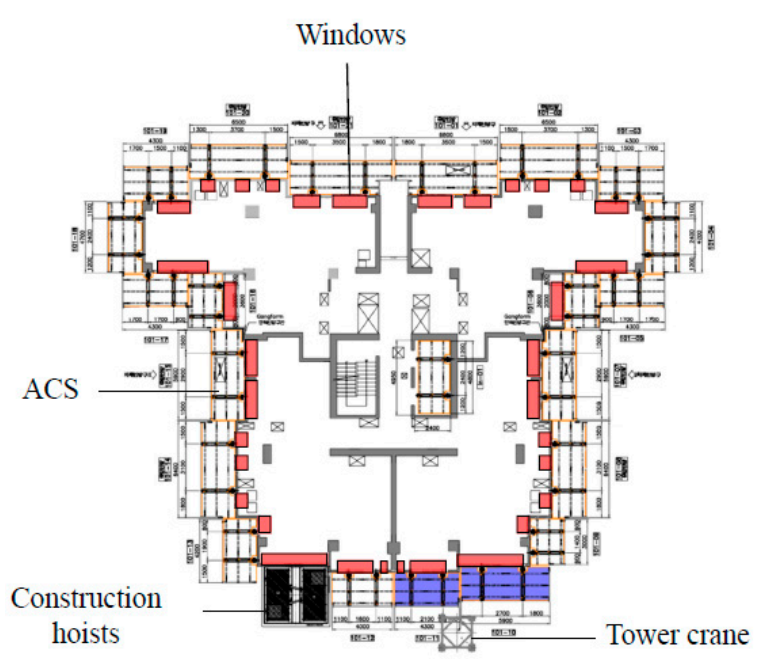

(a)

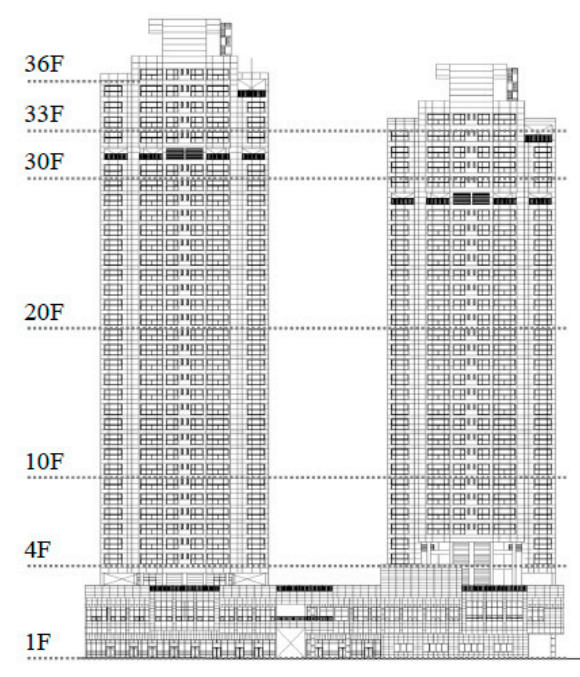

(b)

Figure 3. Case project: (a) layout plan of equipment; (b) cross section of the case project.

\subsection{AWW Method Application}

Figure 4 shows Building A, subject to the AWW method. The method was used for 20 units of the ACS where the walk plate was extended to the $(\mathrm{N}-3)$-th floor. The added work plate was made of aluminum bars, walk plates, and a handrail. Pollution prevention plates were installed on the $(\mathrm{N}-1)$-th and $(\mathrm{N}-2)$-th floors to prevent installed windows from being polluted by concrete paste (Figure $4 \mathrm{~d}$ ).

Two units of the ACS located above the construction hoist were installed with only gangform without work plates (Figure 4c). The gangforms were raised by the tower crane. The cycle of extending the hoistway was the same as that for raising the ACS at an interval of one floor. Wall ties fixing the hoistway to the wall were installed at intervals of two floors.

Figure 5 shows the process of the AWW method. Structural work for each floor was performed over six working days. Formwork, rebar work, and concrete placement were conducted on the N-th floor while curing took place on the $(\mathrm{N}-1)$-th floor. On the $(\mathrm{N}-2)$-th floor, $50 \%$ of the supports and forms were dismantled. On the ( $\mathrm{N}-3)$-th floor, the remaining supports were dismantled and lifted to the N-th floor. Structural work was carried out in the same way as the conventional method, and only forms were removed on the $(\mathrm{N}-2)$-th floor in advance for window work.

The window work for each floor was also conducted within the same six working days as the structural work. This work consisted of installing, filling, and caulking window frames and installing glass. First, window frames were lifted and installed on the ( $\mathrm{N}-2)$-th floor (Figure 4a). Then, filling, caulking, and glass installation were performed on the $(\mathrm{N}-3)$-th floor (Figure $4 \mathrm{~b})$. A window crew performed the installing, filling, and caulking of the window frames and installed the glass. To ensure work continuity, a crew performed four processes for 4 days in the building, and after the crew finished window work on Building A, they immediately began working on Building B. No safety facilities for openings were installed because the entire workspace was enclosed by the ACS and the windows. 


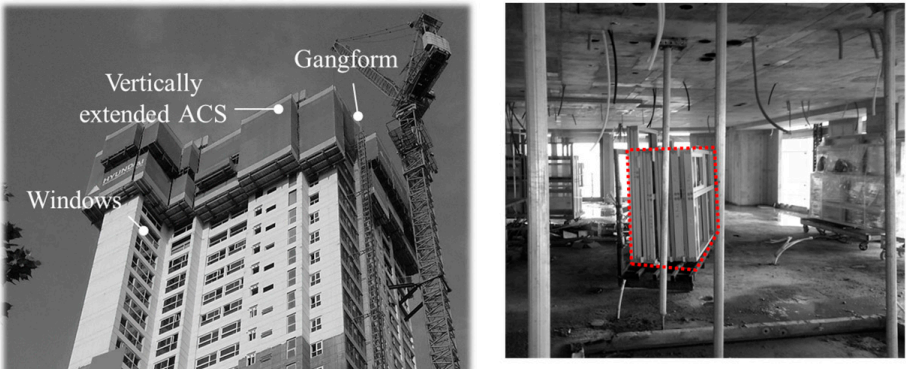

(a) Preparation of windows

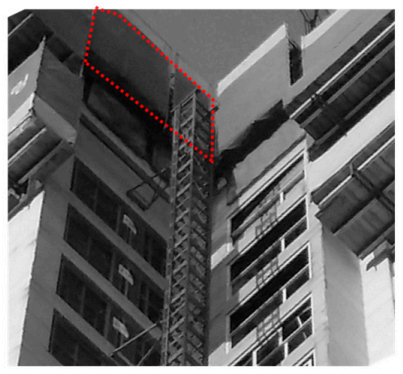

(c) Gangform above construction hoist

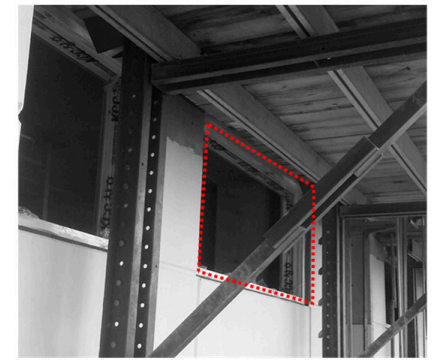

(b) Window installation

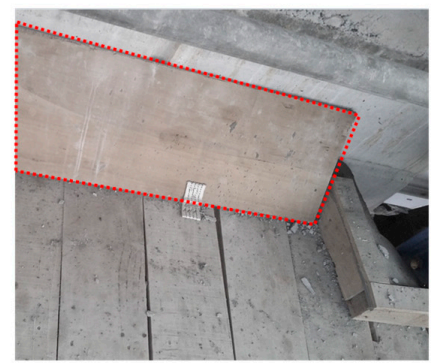

(d) Pollution prevention plate

Figure 4. The AWW method in the case project.

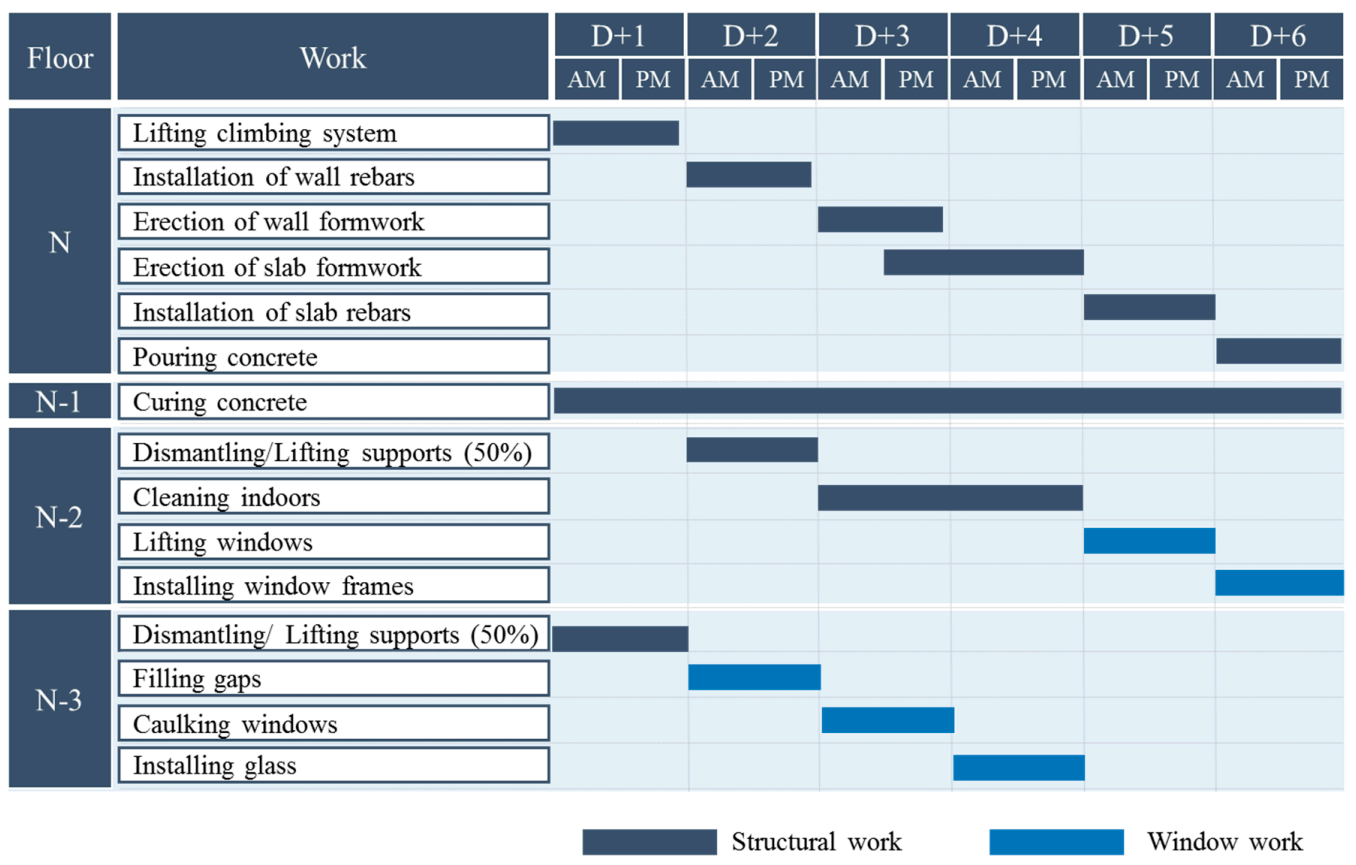

Figure 5. Construction process of the AWW method.

\subsection{Results}

Figure 6 compares the conventional window work method and the AWW method in terms of the duration of construction. In total, there were 24 more working days of window work with the AWW method than with the conventional method. This was because window work using the AWW method has a shorter cycle than that of the conventional method. However, the start time of window work began earlier using the AWW method compared with the conventional method because window work began as soon as the ACS was installed, while window work using the conventional method does not start until structural work reaches the 8th floor. Moreover, window work using the AWW method 
was completed 48 days earlier than it is using the conventional method because the delay caused by dismantling the ACS after the curing of the top floor structure is eliminated. Furthermore, internal finishing works requiring curing, such as masonry and plasterwork, were completed earlier than with the conventional method because of the speeding-up of curing by the windows, which were installed in advance and therefore blocked the outside cold air in the winter. Accordingly, the duration of internal finishing works was shorter by 4 days compared with the conventional method. Consequently, finishing works were conducted earlier by reducing the duration of curing and performing window work in advance, thereby decreasing the entire period of construction by 52 days.

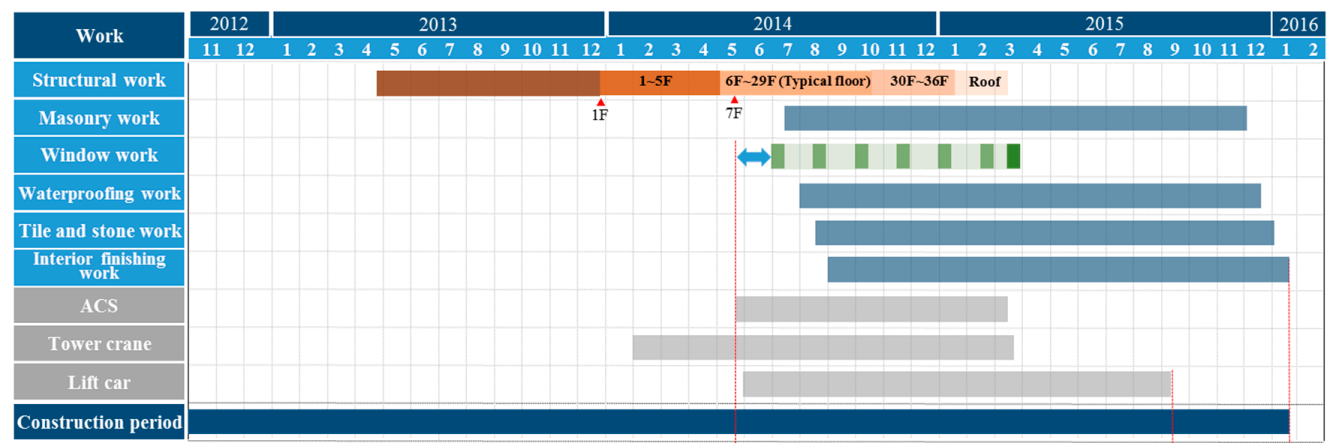

(a)

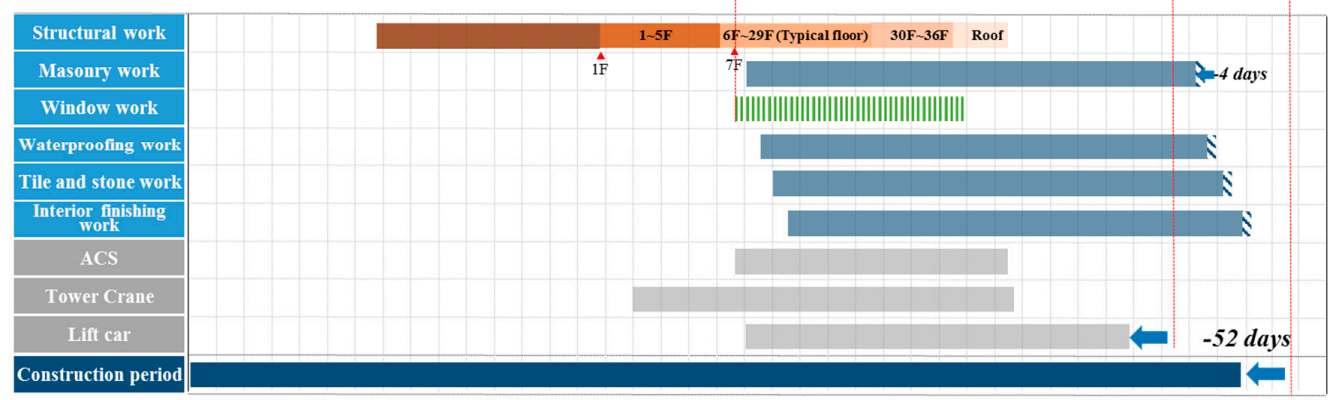

(b)

Figure 6. Comparison of project schedules: (a) conventional method; (b) AWW method.

Table 1 shows the cost variations by applying the AWW method compared with the conventional method. Costs increased in three way. One was the increase in labor cost for window work. First, the quantity of window work per floor in the project was approximately $60 \%$ of the quantity of window work that could be performed by a crew in a day. This increased the total number of working days for window work by 24 days because of the decreased productivity of window work. The increase in cost was $\$ 25,455$. Second, the cost of construction hoist operation increased. Because the number of required extensions of the hoistway and wall ties increased by 1.5 times, the labor cost and the material cost increased by $\$ 1364$ and $\$ 455$, respectively. Finally, the equipment rental cost for adding a level of work plate to the ACS increased. The ACS was extended vertically by a total of 18 units, increasing the cost by $\$ 24,545$.

However, other costs were reduced. First, the equipment rental cost for the suspended working platform used for external caulking work was eliminated because the caulking work was performed on the ACS. The cost of renting the suspended working platforms for 14 days was reduced by $\$ 4073$. Second, the material costs of safety facilities decreased because openings were closed by windows. Safety nets and guardrails to prevent accidents involving falling workers and dropping objects were not required; neither were dust filter nets to prevent air pollution around the site by dust scattering. Costs therefore decreased by $\$ 99,179$. Finally, the equipment rental cost for construction hoists was reduced by the decrease in the overall duration of construction. The cost of renting construction hoists decreased by $\$ 31,491$ because the construction period was reduced by 52 days. 
In sum, the reduction in costs of $\$ 134,743$ was greater than the increase of $\$ 51,819$; overall costs were therefore reduced by $\$ 82,924$.

Table 1. Estimated cost savings by applying the AWW method compared with the conventional method.

\begin{tabular}{|c|c|c|c|c|c|c|}
\hline & \multirow{2}{*}{\multicolumn{2}{|c|}{ Items }} & \multicolumn{4}{|c|}{ Cost Change (\$) } \\
\hline & & & Labor & Materials & Equipment & Total \\
\hline \multirow{3}{*}{ Cost increases } & Window work & $\begin{array}{l}\text { Installation labor } \\
\text { Construction hoist }\end{array}$ & $\begin{array}{c}25,455 \\
1364\end{array}$ & 455 & & $\begin{array}{c}+25,455 \\
+1819\end{array}$ \\
\hline & Structural work & ACS & & 24,545 & & $+24,545$ \\
\hline & \multicolumn{2}{|c|}{ Subtotal (b) } & 26,819 & 25,000 & - & $+51,819$ \\
\hline \multirow{5}{*}{ Cost reductions } & Window work & Suspended platform & & & 4073 & -4073 \\
\hline & Safety work & $\begin{array}{c}\text { Safety nets } \\
\text { Safety handrails } \\
\text { Safety screens }\end{array}$ & $\begin{array}{l}26,771 \\
16,426 \\
29,229\end{array}$ & $\begin{array}{c}23,184 \\
3230 \\
339 \\
\end{array}$ & & $\begin{array}{l}-49,955 \\
-19,656 \\
-29,568 \\
\end{array}$ \\
\hline & Finishing work & $\begin{array}{c}\text { Tower crane } \\
\text { Construction hoist }\end{array}$ & & & $\begin{array}{c}28,364 \\
3127\end{array}$ & $\begin{array}{c}-28,364 \\
-3127\end{array}$ \\
\hline & \multicolumn{2}{|c|}{ Subtotal (a) } & 72,426 & 26,753 & 35,564 & $-134,743$ \\
\hline & \multicolumn{2}{|c|}{ Total Reduction (a-b) } & 45,607 & 1753 & 35,564 & $-82,924$ \\
\hline
\end{tabular}

\section{Discussion}

The AWW method reduced duration and cost by eliminating process gaps between structural and window processes. The main reduction was achieved by continuously installing windows directly after structural work. The AWW method also provided a stable environment that was closed with windows for finishing work, thereby reducing the risk of delays by rework. The cost of window work increased, but overall costs of construction were reduced by eliminating additional safety facilities. Because the cost of safety facilities increases as the numbers of gaps and floors increase, the AWW method used in large buildings is expected to offer greater overall cost savings.

The application of the AWW method also contributed to improved work safety and fewer civil complaints. In the case project, no dropping or falling accidents occurred during the construction period, even though no external safety facilities were installed. In addition, even though the case project was performed in an urban setting, the number of civil complaints about dust and noise because of the structural work decreased by approximately $70 \%$ compared with the sites of other buildings of about the same size as that of this case study. This prevention of dust diffusion to the outside reduces air pollution in the vicinity of the construction site. This is because windows installed earlier eliminated unintentional falling and dropping, and effectively prevented dust and noise from being released to the outside. Furthermore, the stable work environment using the ACS reduced the number of window caulking flaws, thereby improving the quality of the window work.

Despite these advantages, several factors should be considered to ensure that the AWW method is applied successfully. First, sufficient windows for one cycle of window work are required to minimize productivity loss. If the quantity of windows for one floor is too small, window work at an interval of two floors or zoning the workspace should be considered. Second, structural work can be delayed if any problem occurs during window work, given that both are conducted at the same time. Thus, efforts should be made to reduce the risk of delaying construction by regularly maintaining the stocks of windows and adjusting the relevant processes through weekly meetings.

\section{Conclusions}

This study introduces a new window work method for tall building construction called the accelerated window work (AWW) method, which employs vertical formwork for tall residential building construction. We described the method with technical details and management elements and show that this method can reduce the duration of construction by starting and finishing window work earlier. The results of the case study showed that (1), by decreasing the process gap between structural 
and window work, the proposed method can reduce the construction duration and (2), by eliminating the need for safety facilities for openings, the AWW method can significantly reduce costs. Moreover, the case study verified the effectiveness of the AWW method in constructing tall buildings in urban areas by increasing safety performance and reducing the noise and released dust, which helped reduce civil complaints. This work contributes to the body of knowledge about window work in tall buildings by introducing and validating a new window work method. It is expected that this new method will be useful for practitioners under schedule pressures and for those specializing in building construction in urban areas where many civil complaints and claims are expected. In future work, we plan to investigate the zoning method to minimize the loss of productivity in the AWW method. Also required is further research on curtain wall work, which is on the critical path for initiating internal finishing works including window work.

Acknowledgments: This research was supported by a grant (18AUDPB106327-04) from the Architecture \& Urban Development Research Program funded by the Ministry of Land, Infrastructure and Transport of the Korean Government.

Author Contributions: Taehoon Kim and Hyunsu Lim developed the research ideas and completed the writing; Chang-Won Kim and Dongmin Lee collected and analyzed data; Hunhee Cho and Kyung-In Kang designed and organized the overall research flow.

Conflicts of Interest: The authors declare no conflict of interest.

\section{References}

1. Thabe, W.Y.; Beliveau, Y.J. HVLS: Horizontal and Vertical Logic Scheduling for multistory projects. J. Const. Eng. Manag. 1994, 120, 875-892. [CrossRef]

2. Lee, D.; Lim, H.; Cho, H.; Kang, K.I. The Study on integrated ACS and lift car system for early beginning of windows work in tall building construction. In Proceedings of the Korea Institute of Building Construction Spring Conference, Korea, 29 May 2014; Korea Institute Of Building Construction: Seoul, Korea, 2014; Volume 14, pp. 72-73.

3. Kim, T.H.; Shin, Y.S.; Lee, U.K.; Kang, K.I. Decision support model using a decision tree for formwork selection in tall building construction. J. Arch. Inst. Korea 2007, 23, 177-184.

4. Bogus, S.M.; Diekmann, J.E.; Molenaar, K.R.; Harper, C.; Patil, S.; Lee, J.S. Simulation of overlapping design activities in concurrent engineering. J. Constr. Eng. Manag. 2011, 137, 950-957. [CrossRef]

5. Chuersuwan, N.; Nimrat, S.; Lekphet, S.; Kerdkumrai, T. Levels and major sources of PM2. 5 and PM10 in Bangkok Metropolitan Region. Environ. Int. 2008, 34, 671-677. [CrossRef] [PubMed]

6. Nel, A. Air pollution-related illness: Effects of particles. Science 2005, 308, 804-806. [CrossRef] [PubMed]

7. Sioutas, C.; Delfino, R.J.; Singh, M. Exposure assessment for atmospheric ultrafine particles (UFPs) and implications in epidemiologic research. Environ. Health Perspect. 2005, 113, 947-955. [CrossRef] [PubMed]

8. Si, D.; Lee, Y. The Construction Project of the Sharp Lakepark in Chungna; Korea Institute of Building Construction: Seoul, Korea, 2012; pp. 44-49.

9. Chung, J.; Lee, S.H.; Yi, B.J.; Kim, W.K. Implementation of a foldable 3-DOF master device to a glass window panel fitting task. Autom. Constr. 2010, 19, 855-866. [CrossRef]

10. Lee, Y.M.; Kim, Y.S. A study for major delay risk factors in curtain wall work of high-rise building using FMEA. J. Arch. Inst. Korea 2011, 27, 189-196.

11. Moon, S.D.; Ock, J.H. A Study on the construction management by design and construction phase for economic improvement of the curtain wall construction. J. Arch. Inst. Korea 2014, 30, 53-62. [CrossRef]

12. Vähä, P.; Heikkilä, T.; Kilpeläinen, P.; Järviluoma, M.; Gambao, E. Extending automation of building construction-Survey on potential sensor technologies and robotic applications. Autom. Constr. 2013, 36, 168-178. [CrossRef]

13. Yu, S.N.; Lee, S.Y.; Han, C.S.; Lee, K.Y.; Lee, S.H. Development of the curtain wall installation robot: Performance and efficiency tests at a construction site. Auton. Robots 2007, 22, 281-291. [CrossRef] 
14. Kang, H.M.; Yi, J.S. A suggestion on the design-build integrated management for revitalization of exterior insulation and finishing system (EIFS)—Based on the Case Study of Apartment Housing. J. Arch. Inst. Korea 2012, 28, 157-166.

15. Lim, H.; Kim, T.; Kim, C.W.; Cho, H.; Kang, K.I. Window Proximity Tracking Method for Tall Building Construction. Procedia Eng. 2017, 196, 76-81. [CrossRef] 